\title{
Details of doctors' registration status on the GMC website
}

\section{David Payne digital editor, readers' editor}

The BMJ, London WC1H 9JR, UK

I contacted the General Medical Council when writing "Google, doctors, and the "right to be forgotten" " because I wanted to clarify what it says on its website when a doctor is cautioned or returned to the register after suspension.

I suspect some requests to Google will be from doctors who at some time faced conduct proceedings. As the feature makes clear, ${ }^{1}$ the expert advisory panel set up by Google will examine professional conduct issues in light of the "right to be forgotten."

Unfortunately the GMC got back to me after my deadline, but this is what the spokesperson said:

"Just for background: we publish all the information about doctors in the public domain on the List of Registered Medical Practitioners (LRMP) on our website. Towards the top right there's a section called 'check a doctor's registration status' and this includes current or historic restrictions or sanctions on a doctor's registration, including the minutes of fitness to practise hearings (unless held in private where a case relates to a doctor's health).
"For further information about this_-we publish what we call our 'publication and disclosure' policies on our website. This outlines how long we publish fitness to practise information about doctors, and paragraphs 6 to 19 cover the relevant points here www.gmc-uk.org/DC4380_Publication_and_disclosure_ policy_36609763.pdf.

"Just one thing I should mention for clarification-if a doctor is erased from the register and then later restored-the original erasure decision would still be published on our website (including the minutes of the hearing)."

Competing interests: None declared.

1 Payne D. Google, doctors, and the "right to be forgotten." BMJ 2015;350:h27. (6 January.)

Cite this as: BMJ 2015;350:h428

๑ BMJ Publishing Group Ltd 2015 